\title{
EVALUATION OF CHANGES IN ELASTIC PROPERTIES OF ANIMAL TRABECULAR BONE FOR MECHANICAL TESTS DEPENDING ON THE STORAGE METHOD
}

\author{
A. Andrzejewska*, T. Topoliński ${ }^{* *}$, A. Mazurkiewicz ${ }^{* * *}$
}

\begin{abstract}
The study presents the results of the evaluation of changes in the elastic modulus of a porcine and bovine trabecular bone depending on the storage method. The bone samples were taken from the porcine and bovine femoral bones. The samples were stored in a $10 \%$ formalin solution and frozen at $-20{ }^{\circ} \mathrm{C}$. The samples were tested immediately after taking, and after 7, 14 and 21 days. A statistical evaluation of the test results was carried out. The results showed that the changes in modulus value in dependence on storage method are not statistically significant.
\end{abstract}

Keywords: trabecular bone, storage method, elastic modulus

\section{Introduction}

Human and animal bone is a composite material consisting of several components serving various functions in the body. Those components may also show different properties, e.g. mechanical properties. A trabecular bone is one of the bone components and is part of the composite material most responsible for providing resistance of the entire bone to aging or metabolic changes. Thus, knowing and evaluating its behaviour under load and the effects of different factors on the behaviour is significant for further studies - usually at the fringe of medical and biological sciences, to maintain the highest possible strength of the bone.

The bone is an organic material which deteriorates gradually and requires special storage methods. The purpose of the study is to evaluate the changes in elastic modulus of porcine and bovine bones for mechanical tests in three weeks depending on the storage method. Since testing the materials taken from human bones requires special procedures and permits, the animal bones are usually used in the mechanical tests, i.e. porcine or bovine bones due to their similarity to the human bones (Mosekilde et al, 1987 and Pearce et al, 2007).

\section{Methods}

The study included 20 bovine and 20 porcine femoral bones. Two samples were taken from each bone. The samples were divided into 4 groups, 20 bovine or 20 porcine bone samples each. The porcine bone samples were collected from the animals of the same breed and at the same age - ca. 6 months. The bovine bone samples were collected from the animals of the same breed aged 32 to 66 months. The bones after slaughter were stored in a freezer. The samples were collected within 24 hours from slaughter.

Assistant Angela Andrzejewska, MSc: Department of Mechanical Engineering, University of Sciences and Technology, Kaliskiego 7 Street; 85-789 Bydgoszcz; PL, e-mail: angela.andrzejewska@utp.edu.pl

** Professor Tomasz Topoliński, Prof. Dr. Eng.: Department of Mechanical Engineering, University of Sciences and Technology, Kaliskiego 7 Street; 85-789 Bydgoszcz; PL, e-mail: tomasz.topolinski@utp.edu.pl

*** Assoc. Prof. Adam Mazurkiewicz, PhD: Department of Mechanical Engineering, University of Sciences and Technology, Kaliskiego 7 Street; 85-789 Bydgoszcz; PL, e-mail: adam.mazurkiewicz@utp.edu.pl 
Elastic modulus was determined immediately after collecting the samples. The samples were stored for 3 weeks with subsequent tests carried out after 7,14 and 21 days.

The samples were collected from the heads of femoral bones. First, the slices were cut perpendicularly to the neck axis and the cylindrical samples $10 \mathrm{~mm}$ in diameter and $10 \mathrm{~mm}$ in height were cut from the slices. Fig. 1 shows the sample collecting method.

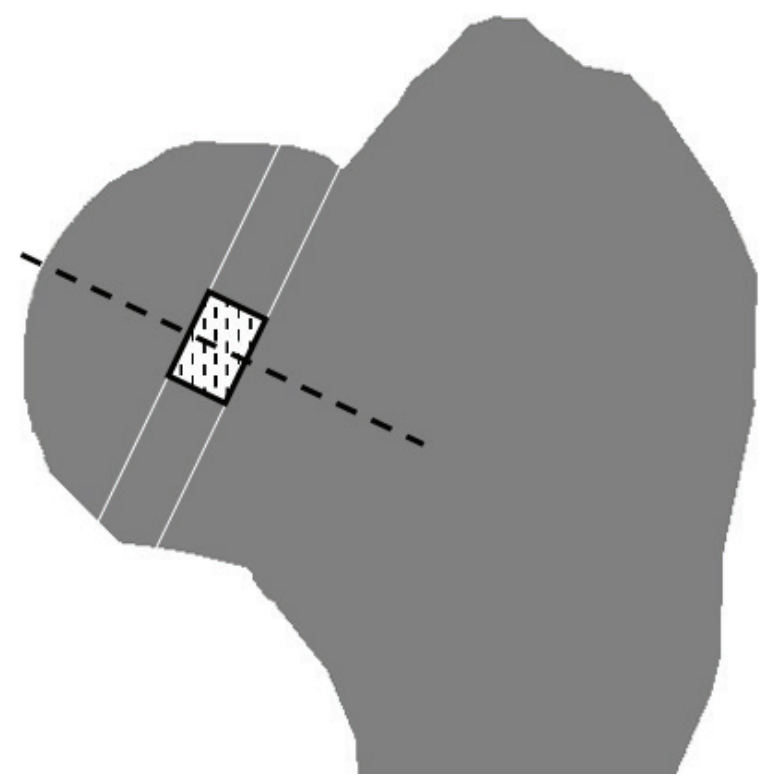

Fig. 1: Samples collecting scheme.

The samples were stored in a buffered $10 \%$ formalin solution at room temperature and frozen at $-20{ }^{\circ} \mathrm{C}$. Initial elastic modulus was determined at room temperature using Instron E3000 testing system (Instron, High Wycombe, England).

An initial $3 \mathrm{~N}$ force was applied to the sample. The strain of the sample at the initial force was taken as a "zero" point. A total of 5 loading cycles were applied until a $0.65 \%$ strain, corresponding to a $0.065 \mathrm{~mm}$ displacement was recorded. A secant modulus for the 5th loading cycle was recorded as the initial elastic modulus.

The Szapiro-Wilk test was performed at $p=0.05$ to check the normality of distribution of the initial modulus values for each group. The distribution of the obtained results in all groups was normal or lognormal confirmed at a specific $\mathrm{p}$-value. Thus, the Kolmogorov-Smirnov test at $\mathrm{p}=0.05$ was used to evaluate the changes in average value of initial modulus after 7, 14 and 21 days. All statistical calculations were performed in "R" software.

\section{Results}

Table 1 and 2 shows the results for each sample group. The average values are higher in the bovine bone sample group. It is result higher weight of an animal the samples were collected from. The porcine bone samples were collected from animals weighing approximately $90 \mathrm{~kg}$, wherein the bovine bone samples were taken from animals weighing 150 to $230 \mathrm{~kg}$ at different age.

Table 1: Values of average values of modulus and its standard deviation obtained for bovine samples.

\begin{tabular}{lcccc}
\hline Storage method & $\begin{array}{c}\text { Initial modulus } \\
(\mathrm{SD}), \mathrm{MPa}\end{array}$ & $\begin{array}{c}\text { Modulus }-7 \text { days } \\
(\mathrm{SD}), \mathrm{MPa}\end{array}$ & $\begin{array}{c}\text { Modulus }-14 \\
\text { days (SD), MPa }\end{array}$ & $\begin{array}{c}\text { Modulus - 21 } \\
\text { days (SD), MPa }\end{array}$ \\
\hline Formalin & $3259(1450)$ & $3228(1414)$ & $3189(1569)$ & $3157(1522)$ \\
\hline Frozen & $3309(1748)$ & $3342(1816)$ & $3231(1796)$ & $3490(1879)$ \\
\hline
\end{tabular}


Table 2: Values of average values of modulus and its standard deviation obtained for porcine samples.

\begin{tabular}{lcccc}
\hline Storage method & $\begin{array}{c}\text { Initial modulus } \\
(\mathrm{SD}), \mathrm{MPa}\end{array}$ & $\begin{array}{c}\text { Modulus }-7 \text { days } \\
\text { (SD), MPa }\end{array}$ & $\begin{array}{c}\text { Modulus }-14 \\
\text { days (SD), MPa }\end{array}$ & $\begin{array}{c}\text { Modulus - 21 } \\
\text { days (SD), MPa }\end{array}$ \\
\hline Formalin & $1853(983)$ & $1742(954)$ & $1812(853)$ & $1785(1007)$ \\
\hline Frozen & $1932(923)$ & $1872(889)$ & $1892(859)$ & $1865(912)$ \\
\hline
\end{tabular}

The Kolmogorov-Smirnov test results show that the changes in average value recorded after 1, 2 and 3 weeks for each group stored in formalin and frozen are statistically insignificant. High values of standard deviation are typical for the trabecular bone (Covin, 1999 and Cichański et al, 2010). Those, however, do not affect the statistic test results.

Figures 2-3 shows average and standard deviation values obtained for bovine and porcine group stored in formalin solution.

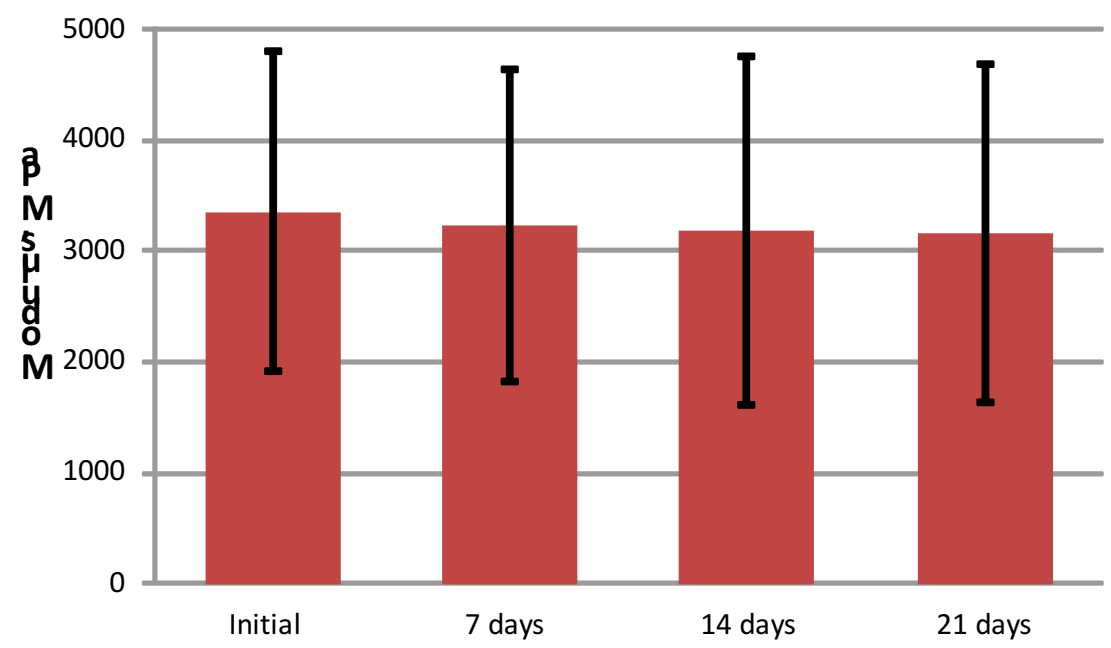

Fig. 2: Average and standard deviation of modulus values for bovine trabecular bone stored in formalin solution.



Fig. 3: Changes in average and standard deviation of modulus values for porcine trabecular bone stored in formalin solution.

\section{Conclusions}

The bones in a human or an animal body are subject to constant temperature corresponding to the body's own temperature, constant humidity etc. The sample properties change immediately after collecting and thus a proper storage method is required. The results provided by some authors show that the storage 
in formalin does not affect the properties of the trabecular bone tissue, others show that the effects are present (Edmonston et al., 1994 and Popperl et al., 1999)

Bone material included in a group of porcine samples used in the tests was very uniform. All animals were part of the same herd, were of the same breed and at a similar age. The living conditions, the diet and the level of activity were also similar. However, those where different for the bovine bone samples collected from animals at a different age and thus it was difficult to determine the effects of other factors on their strength properties.

The results show that none of the methods significantly affect the changes in elastic modulus and all can be used to store the trabecular bones for up to 3 weeks. Due to the similarity of the trabecular bone, in particular the porcine bone to the human bone, it can be safely assumed that the methods can also be used to store the samples collected from the human bones.

Due to the daily activities of humans and animals, the bones are subject to loads variable in time. It might be an issue, because the tests under cyclic loading especially with a constant amplitude usually take longer (An and Draugh, 1999). Thus, the test with a gradually increasing amplitude are also used for the bones samples (Topoliński et al., 2011 and 2012). During the tests, the sample should be stored in a container filled with a suitable preserving fluid, not in a thermal chamber, to prevent drying which may affect the test results. From among the tested storage methods, the best method is to store the samples in a formalin solution, which allows to keep the sample in the container at constant temperature maintained throughout the test. It reduces the effects of external factors which may affect the test results.

\section{References}

An, H. and Draugh, R. (1999) Mechanical testing of bone and the bone-implant interface. CRC Press, New York.

Cichanski, A., Nowicki K., Mazurkiewicz, A. and Topoliński T. (2010) Investigation of statistical relationships between quantities describing bone architecture, its fractal dimensions and mechanical properties. Acta of Bioengineering and Biomechanics, 12, 4, pp. 69-77.

Covin, S. (1999) Bone mechanics handbook - second edition. CRC Press, New York.

Edmondston, S. J., Singer, K. P., Day, R. E., Breidahl, P. D. and Price, R. I. (1994) Formalin fixation effects on vertebral bone density and failure mechanics: an in-vitro study of human and sheep vertebrae. Clinical Biomechanics, 9 ,3, pp. 175-179.

Mosekilde, L., Kragstrup, J. and Richards, A. (1987) Compressive strength, ash weight, and volume of vertebral trabecular bone in experimental fluorosis in pigs. Calcif Tissue Int., 40, 6, pp. 318-22.

Pearce, A.I., Richards, R.G., Milz, S., Schneider, E. and Pearce, S.G. (2007) Animal models for implant biomaterial research in bone: A review. Eur Cell Mater., 2, 13, pp. 1-10.

Pöpperl, G., Lochmüller, E., Becker, H., Mall, G., Steinlechner, M. and Eckstein, F., (1999) Determination of calcaneal ultrasound properties ex situ: reproducibility, effects of storage, formalin fixation, maceration, and changes in anatomic measurement site. Calcif Tissue Int., 65, 3, pp. 192-7.

Topolinski, T., Cichanski, A., Mazurkiewicz, A. and Nowicki K. (2011) Fatigue Energy Dissipation in Trabecular Bone Samples with Step-wise-Increasing Amplitude Loading. Materials Testing, 53, 6, pp. 344-350.

Topolinski, T., Cichanski, A., Mazurkiewicz, A. et al. (2012) Applying a stepwise load for calculation of the S-N curve for trabecular bone based on the linear hypothesis for fatigue damage accumulation. Mater. Sci. Forum 726, pp. 39-42, doi:10.4028/www.scientific.net/MSF.726.39. 